\title{
Post incident analysis report: Lacrosse Docklands, 25 November 2014
}

\author{
Greg Badrock \\ Metropolitan Fire and Emergency Services Board, Melbourne, Australia
}

\section{EXECUTIVE SUMMARY}

This Post Incident Analysis (PIA) provides a detailed account of the fire incident that occurred at the Lacrosse building on 25 November 2014.

It includes information compiled by MFB Fire Safety Officers investigating the sequence of fire events, the suitability of building materials used in construction, performance of installed fire safety equipment, evacuation of the building and fire causation.

The main observations are:

- External wall cladding (Alucobest) rapid fire spread.

- Use of combustible external wall cladding on Type A construction.

- Building material design, selection and installation.

- High occupancy rate.

- Mass evacuation necessary due to fire development and spread.

- Emergency Warning and Intercommunication System (EWIS) was compromised.

- Sprinkler system operated well beyond its designed capability.

- Sprinklers were not required on the balconies under the Building Codes of Australia (BCA).

\section{FIRE CALL 15657}

At 02:24 hours on Tuesday morning 25 November 2014, MFB fire crews responded to an exchange call for a reported apartment fire at 673 - 675 La Trobe Street, Docklands. When the first fire crews arrived on scene at 02:29 hours, they observed that the fire had already extended up the external walls and balconies over approximately 6 levels. At 02.35 hours, only 6 minutes later, crews reported back that fire had reached the roof of the building above the $21^{\text {th }}$ floor.

The fire scenario and fire behaviour encountered by the attending MFB fire-fighters on that morning is not a scenario commonly encountered by MFB crew attending high-rise buildings. Rapid vertical fire spread up the building appeared to be directly associated with the external façade of the building, rather than associated with the internal parts or extensive fuel loads stored on many of the balconies.

Due to rapid fire spread and penetration into internal parts of the building over many levels, the entire building was evacuated resulting in more than four hundred evacuees assembling in La Trobe Street. It appears the rapid fire spread caused the EWIS to be compromised on most fire affected levels, preventing it from operating as designed on those levels. Fire crews were therefore forced to enter every level and alert occupants of each apartment to ensure total evacuation.

This is an Open Access article distributed under the terms of the Creative Commons Attribution License 2.0, which permits unrestricted use, distribution, and reproduction in any medium, provided the original work is properly cited. 


\section{MATEC Web of Conferences}

After the fire, it was observed that many apartments contained bedding arrangements indicating a higher occupancy level than what would normally be expected. This resulted in increased combustible fuel loads due to the greater amount of personal belongings. It was fortunate that the installed fire sprinkler system operated well above its designed capability preventing further internal spread.

MFB fire investigators concluded that the fire was started by a cigarette butt disposed of in a plastic container located on the top of a timber topped outdoor table, positioned towards the southern end of apartment 805 balcony.

\section{FIRE INCIDENT EVENTS}

The following information was compiled after MFB fire safety officers interviewed a number of firefighters and occupants who were present during the incident. The Bureau of Meteorology (BoM) records indicate that the temperature during the night was around 12 degrees, with a westerly wind of 20 to 30 kilometres per hour. At approximately 01:30 hours on the morning of Tuesday 25 November 2014, an occupant from Apartment 805 of the building, claims he investigated the smell of smoke. After checking the kitchen and making sure the gas stove was turned off, he returned to bed. Sometime later, the same occupant was woken by two other house mates who had discovered the fire burning on the balcony.

From inside the apartment, he could see a fire on the right hand side (south) of the balcony. The occupants of the apartment unsuccessfully attempted to extinguish the fire using a container of water. All of the occupants from Apartment 805 then evacuated the apartment via the buildings northern end isolated fire stairs.

At 02:24 hours, MFB fire crew responded to an exchange call for a reported apartment fire at 673 La Trobe Street, Docklands. The fire indicator panel history log shows activation of the Level 8 fire sprinkler flow switch at 02:25 hours, which also generated an alarm to the MFB. Several exchange calls followed confirming that the building was well alight and the fire was spreading rapidly up the building. Refer to call history Appendix 2 of the full report.

When the first fire crew arrived on scene at 02:29 hours, they observed fire travelling upwards rapidly and involving about six floors. They also observed that the fire was burning up the external wall cladding and spreading onto the balcony on each level. By this time a number of people had already evacuated and had congregated outside the building entry in La Trobe Street.

The occupants from Level 6, Apartment 605 reported later to fire-fighters, seeing fire embers and flaming debris falling from levels above their apartment and igniting materials on their balcony. They then evacuated the building (see Fig. 1).

At 02:30 hours, the Senior MFB Officer in attendance provided the following word back; "Structure Fire, Respond $3^{\text {rd }}$ Alarm". This was followed by a message that crew wearing breathing apparatus and equipped with hose lines were entering the building to evacuate all occupants and investigate the extent of fire spread. By 02:35 hours, it was reported that the fire had spread to Level 21 via the external face of the building. At 02:38 hours, the status of the alarm was upgraded to a $4^{\text {th }}$ alarm.

Fire-fighters confirmed that the sprinkler system operating within the apartments had held the fire in check, and was preventing further internal spread and fire development. Fire-crew used hose lines connected to internal hydrants and portable fire extinguishers to totally extinguish fires on Levels 10 and 19.

An MFB aerial appliance referred to as a "Ladder Platform" was set up on the La Trobe Street overpass and at approximately 02:46 hours, was operational and had water onto the fire. The water stream from the water monitor on this appliance was able to reach all levels on the building, making extinguishment of the burning façade more efficient. With several hundred civilians from the building assembling on the north side of La Trobe Street, MFB Officers arranged their evacuation to a sheltered area at Southern Cross Station.

At the height of the fire, MFB committed 122 personnel, 22 appliances, 3 aerial appliances and 4 specialist vehicles. 
$2^{\text {nd }}$ International Seminar for Fire Safety of Facades, Lund (Sweden), 2016

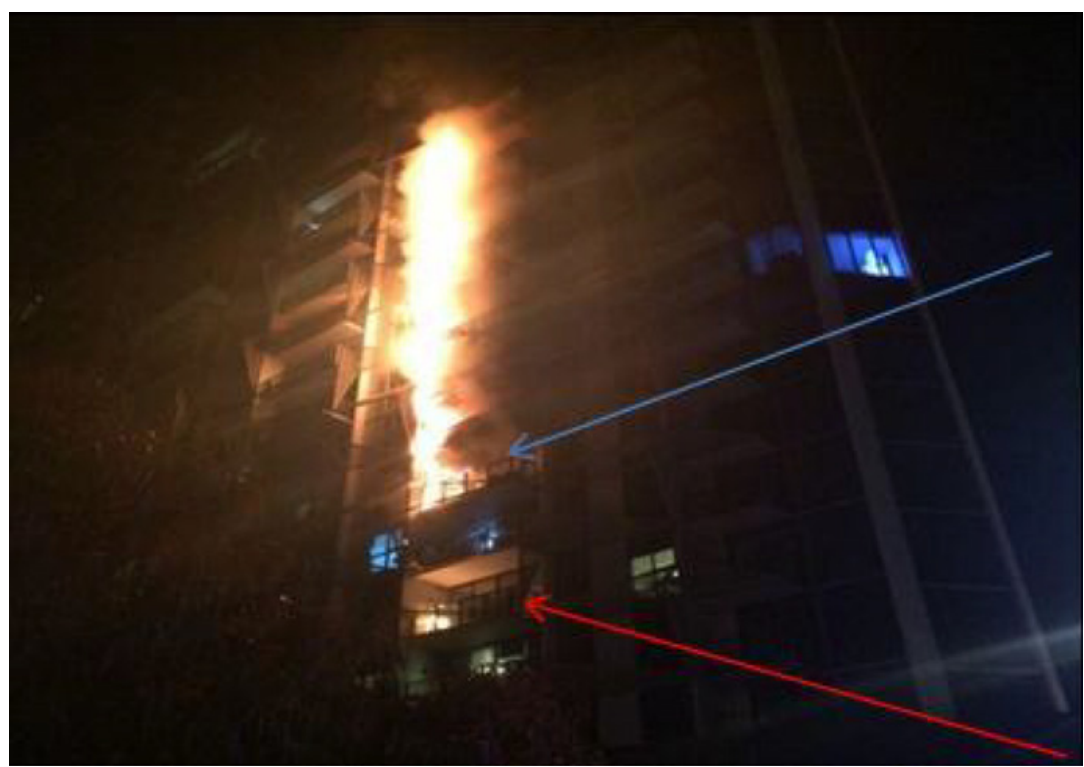

Figure 1. Picture of the fire on level 6 (red arrow) and fire on level 8 (point of origin - blue arrow) extending up to level 14 (02:29).
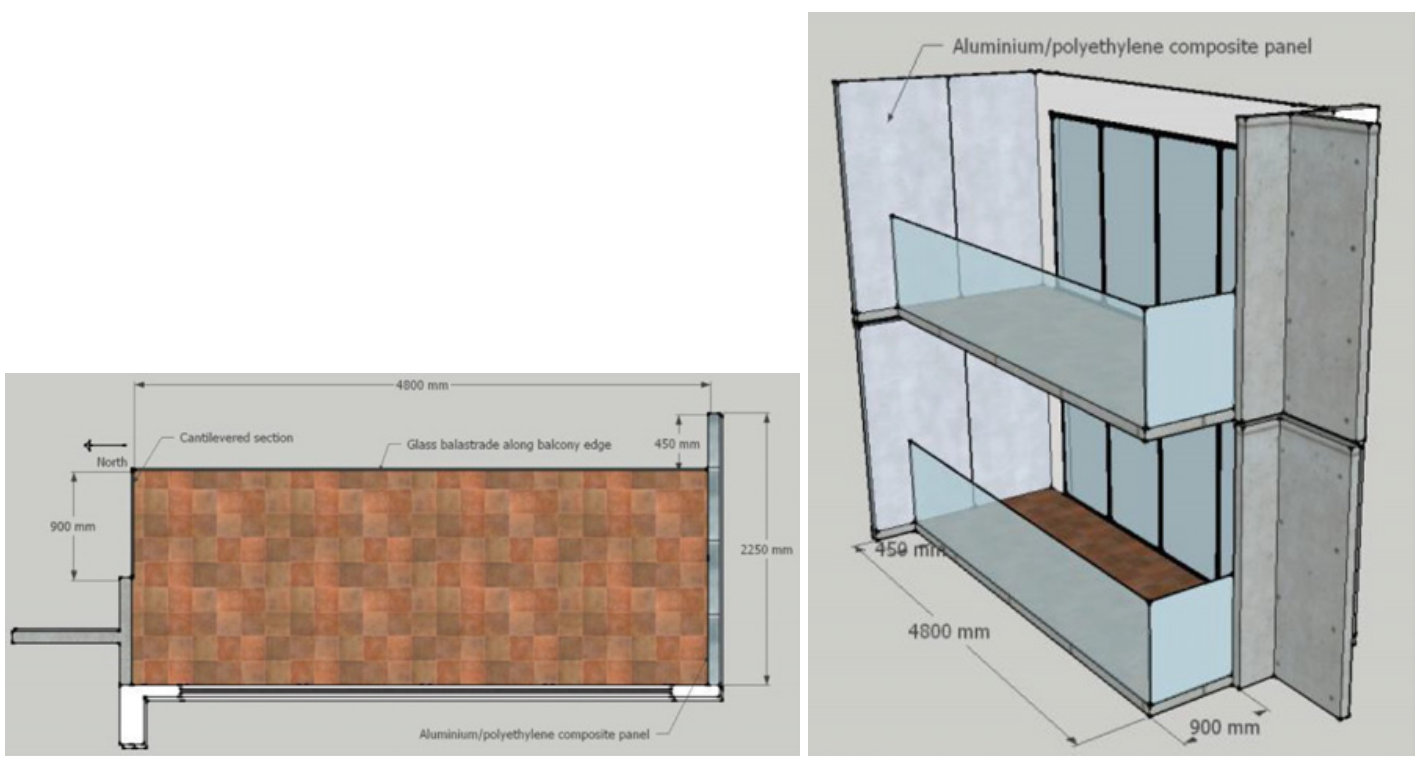

Figure 2. Scheme of balcony and external wall.

\section{BUILDING CONSTRUCTION ASSESSMENT}

\subsection{Balcony and external wall construction and characteristics}

The apartments known as Apartments 605 to 2105 are located in vertical alignment from the $6^{\text {th }}$ floor to the $21^{\text {th }}$ floor on the east façade of the building. They include suspended concrete balconies of 


\section{MATEC Web of Conferences}

approximately 1.8 metres deep $\times 4.7$ metres wide. A double-glazed sliding door assembly is fitted in the external wall of the building and provides access to the balcony.

The northern end of these balconies are bounded by $900 \mathrm{~mm}$ concrete panels, which leaves the remaining $900 \mathrm{~mm}$ balcony depth cantilevering out beyond the building face. A 1 metre high glazed balustrade is fitted to the remaining northern edge of the balconies and returns along the length of the eastern edge and butts into the southern wall.

In contrast to the northern end of these balconies, the walls at the southern end of the balconies extend out approximately 2.25 metres and some $450 \mathrm{~mm}$ from the external face of the balconies.

These walls are built of lightweight steel stud construction. The internal face of the walls are lined with two layers of $13 \mathrm{~mm}$ standard grade gypsum plasterboard, contain insulation batts, along with a combustible PVC stormwater downpipe and several combustible electrical/television cabling and input face plates. The external face is lined with a $4 \mathrm{~mm}$ aluminium/polyethylene composite panel façade containing a polyethylene core.

MFB Fire Investigators removed a large sample of the aluminium/polyethylene composite panel façade, fitted to the southern end of the balconies, for further investigation. The removed section of panel contained manufacturer labelling and serial identification on the internal face indicating the following: “ALUCOBEST 11060167 HY 1034 mm 2011/06/17 20:51:45".

The product is believed to incorporate a Polyethylene core material. The Alucobest Technical Manual provided on the web link at www. alucobest.com, indicates that it is a product manufactured by a China based company titled Shanghai Huayuan New Composite Materials Co. Ltd. The MFB reasonably believes this to be the product installed to the southern end of the balconies of Rooms 605-2105 and is likely to be the same product installed throughout the remainder of the façade of the building. Alucobest Aluminium/Polyethylene Composite Panel - Fire Behaviour Properties. As mentioned above, it is assumed the Alucobest panel taken from the Lacrosse building is the standard grade, and not the "Fire Resistant" model, detailed on the Alucobest Technical Manual. All references made to the "Fire Resistant" range is referred to as Alucobest FR. The sample of panel does not include manufacturer labelling to indicate the sample is from the Alucobest FR range. There is no discussion or reference made to fire behaviour tests of the standard grade Alucobest aluminium/polyethylene composite panel in the available Alucobest technical manual. It appears that this product has not been tested in accordance with AS1530.1:1994 - Combustibility Test for Materials.

\subsection{Testing of Alucobest to 1530.1}

MFB forwarded a sample of the "Alucobest" (ACP) taken directly from the façade of the Lacrosse building to the CSIRO test facility in North Ryde, NSW. On April 1, 2015 the CSIRO determined the following indicative test outcomes:

"Observations: Sustained flaming was observed on the specimen at 55 seconds into the test. The test was terminated at 93 seconds due to excessive flaming and smoking.

Designation: The material is deemed COMBUSTIBLE according to the test criteria

specified in Clause 3.4 of AS 1530.1:1994."

For the full CSIRO test report see Appendix 3, of the full PIA report

\section{ISSUES}

\subsection{External wall cladding (Alucobest) rapid fire spread}

\subsection{MFB comment:}

First-hand accounts from attending MFB fire-fighters and residents of the building, describe the fire as appearing to be associated directly with the façade of the building rather than the combustible contents 
and storage on the external balconies. Burning and flaming facades on high-rise buildings is not a common phenomenon witnessed by the MFB and is of genuine concern. Of even greater concern is the speed and intensity of the fire spread.

The MFB Fire Investigation team have determined that the fire originated on the balcony of the $8^{\text {th }}$ floor. The FIP history log shows activation of the Level 8 sprinkler flow switch at 02.25 hours, one minute later than an exchange call received by the MFB. Fire crews arrived on scene at 02.29 hours, some five minutes later and reported vertical fire spread to approximately the $14^{\text {th }}$ floor. At 02.35 hours, MFB crew reported that the vertical fire spread had reached the roof. From the timeline described above, it is reasonable to derive external vertical fire spread occurred from the $8^{\text {th }}$ floor to the roof above the $21^{\text {th }}$ floor within 10 to 15 minutes, penetrating the adjacent internal rooms on all floors. In the case examined in this report, the upward vertical spread of fire was restricted only by the height of the building. If the building and the construction of the external walls continued to a greater height of upward of 21 storeys, it is highly probable fire spread would have continued beyond 21 storeys.

\subsection{Use of combustible external wall cladding on Type A construction}

\subsection{MFB comment:}

Due to the use and number of storeys, Stage 1 of The Lacrosse Apartment Building is considered a building requiring Type A construction when determined under $\mathrm{C} 1.1$ of the BCA. In accordance with the deemed-to-satisfy requirements of Specification C1.1 of the BCA, external walls of Type A buildings must be non-combustible, notwithstanding any requirement for fire rating. Non-combustible is a defined term in the BCA and is defined as the following:

Applied to a material - not deemed combustible as determined by AS1530.1 - Combustibility Test for Materials; Applied to construction or part of a building - constructed wholly of materials that are not deemed combustible.

Additionally, a material may be considered non-combustible under $\mathrm{C} 1.12$ of the BCA, if it meets the defined criteria within that clause. Standard grade Alucobest aluminium/polyethylene composite panel does not meet the criteria and nor is it likely that it has been successfully tested in accordance with AS1530.1. Therefore, a building permit application specifying the use of standard grade Alucobest aluminium/polyethylene composite as an external wall cladding system, proposes an alternative solution to the deemed-to-satisfy requirements of the BCA. Evidence of suitability for the material and form of construction must be obtained in accordance with A2.2 of the BCA, to demonstrate it meets the relevant performance requirements. This may be in the form of a Certificate of Conformity/Accreditation. The MFB have not been able to gain such documentation for the Alucobest range and these products are not included in the ABCB - Register of CodeMark Certified Products.

\subsection{Building material design, selection and installation}

\subsection{MFB comment:}

The MFB has been unable to obtain the complete building approval documentation as the total of the approved drawings, specifications was not available at the Council Offices. The MFB was therefore unable to substantiate if Alucobest panel was specified in the approved drawings or a competitor product.

Anecdotally, many of the same/similar products in Australian competitors range have obtained Certificates of Conformity under the ABCB - CodeMark Scheme. The conditions on the certificates generally require mechanical fixing systems for the panels on Type A and B buildings, in lieu of adhesive flat tape as used on the Alucobest product on the Lacrosse Building. The MFB have been informed by industry representatives that they believe this requirement is to prevent delamination of the aluminium face sheet, which can expose the combustible core material to the effects of fire. 
Brigade member accounts, along with video footage, details large flaming flat sheets falling from the building façade.

Additional to the combustible cladding, the lightweight external walls at the southern end of balconies include combustible $100 \mathrm{~mm}$ PVC stormwater downpipes and associated lagging within the core of the wall. The downpipes are connected to the drains housed in the balcony floors to drain stormwater collected on the surface of the balconies. A fire collar is installed around the PVC downpipe penetration, through the concrete balcony, to retain the required fire resistance level.

Inspections conducted after the day of the subject fire incident revealed that many fire collars failed to operate as designed i.e. did not close sufficiently to prevent fire spread to connecting levels.

\subsection{High occupancy rate}

\subsection{MFB comment:}

The occupancy of many of the apartments appeared to be in excess of what would normally be expected in a two bedroom apartment and what a two bedroom apartment is designed for. During investigations it was identified that some apartments had sleeping arrangements for up to eight people. This led to a greater level of storage of personal belongings within the apartment and on the apartment balcony.

As a result, the higher fire fuel load has allowed for a more intense fire to develop on the balcony. In this instance the sprinkler system did not cover the balcony so the fire was able to develop to the point of causing the glass panels located between the apartment's living room and the balcony to break and expose the internal rooms to fire. Fortunately in this instance, the sprinkler system installed within each apartment prevented major internal fire spread.

Additionally, high occupancy of apartments can impact on safe evacuation of occupants in the event of an emergency. Some of the apartments in this building had temporary structures assembled around the bed to provide privacy. These light weight structures, along with other furnishings and contents, may impede clear egress from the apartment making it difficult for occupants to exit safely.

\subsection{Mass evacuation necessary due to fire development and spread}

\subsection{MFB comment:}

External wall construction and materials used in this building allowed for rapid vertical fire spread, involving a relatively large portion of the high-rise building as opposed to a single level. In light of this fire, Officers had no choice but to evacuate the entire building. Over 400 evacuees were assembled in La Trobe Street before the MFB identified that a large sheltered evacuation centre would be needed.

Initially the evacuees were escorted from La Trobe Street to the Southern Cross Station bus centre, where they were monitored by Ambulance Victoria and provided with water and blankets. The MFB Incident Management Team (IMT) called for the response of the Municipal Emergency Response Officer (MERO) and the establishment of an Emergency Relief Centre, (ERC). During the morning it was decided to use Etihad Stadium as a recovery and information centre and all evacuees were transferred to this location.

The care and management of the displaced occupants also presented a challenge for the MFB and other agencies. During the MFB debrief fire-fighters indicated that it was a difficult process to register and account for all occupants, as some evacuees did not speak English and some did not understand the reason for providing their name and address.

Due to the fire damage and the fire systems being inoperable, the occupants were unable to return to their apartment for an extended period of time. Some occupants were displaced for a longer period while the building underwent structural repair. 


\subsection{Emergency Warning and Intercommunication System (EWIS) was compromised}

\subsection{MFB comment:}

In the hours after the fire, MFB personnel conducted numerous interviews with occupants and firefighters that were involved in the initial fire response. Many of the occupants spoken to said they did not hear alarms. These occupants said they were awoken to the fire by "screaming, banging and other loud noises".

The remaining witnesses fell into two different groups. One group commented that the alarms came on for a few seconds only or they could hear alarms but they were very quiet and distant. The other group said they heard the alarms and evacuated. Approximately 10 minutes after the first appliance arrived on scene a fire-fighter used the EWIS PA facility to make an evacuation announcement. No witnesses questioned reported hearing this message. Subsequent investigations found that the following scenario resulted in the EWIS“s failure.

Directly above the balcony air-conditioner compressor units (south wall), is a metal exhaust grill. The grill is connected to a formed sheet - metal collection box located in the ceiling space above Bedroom 2. The collection box is approximately $600 \mathrm{~mm}$ wide, $250 \mathrm{~mm}$ high and $600 \mathrm{~mm}$ deep. Two $150 \mathrm{~mm}$ non-insulated aluminium flexi ducts were connected to the collection box from the bathroom exhaust fans. A EWIS sounder was located in the ceiling of Bedroom 2 and directly adjacent to the above exhaust collection box. This design arrangement was typical for all apartments in vertical alignment from 605 to 2105 .

The EWIS system is designed and installed as per Australian Standard AS1670.4. This Standard requires all wiring between the EWIS"s main panel and the evacuation zone to be fire rated. The zone wiring itself is not required to be fire rated, instead non-fire rated thermal plastic sheath (TPS) wire is used.

As identified earlier, the fire started on the balcony of Apartment 805 on Level 8. Hot gases as a result of the fire, entered the ceiling space over Bedroom 2 via the external wall grill and compromised the wiring and designated sounder of the EWIS (Appendix 5) full report. This resulted in a fault in the speaker loop and subsequent failure of the entire sounder system on the entire $8^{\text {th }}$ level. This has been confirmed by Representatives from the installation/maintenance company.

Based on witness statements and subsequent investigations, it is believed that the EWIS on Level 8 and 9 operated for approximately 30 seconds after the FIP received its first activation transmission from the smoke detector outside Apartment 805. It then failed due to the fire compromising the system. It is also believed that the EWIS operated on Level 7 for approximately 5 minutes before it too failed.

As described earlier the fire burnt up the side of the building extremely fast. It is believed that the fire caused the EWIS"s system to fail on most of the levels ahead of the cascading EWIS evacuation sequence that was ascending the building. This would suggest that those who said they heard the alarm and evacuated would have been located below Level 9.

\subsection{Sprinkler system operated well beyond its designed capability}

\subsection{MFB comment:}

In total, 26 fire sprinkler heads activated over 16 floors during the fire incident. As the fire spread to each level, fire sprinkler heads generally activated within the lounge and bedroom 2 and prevented internal fire spread and development into apartments. This put a significant demand on the installed sprinkler system and associated water supply. Additionally, two internal fire hydrants were used by fire-fighters to extinguish fires not extinguished by the sprinklers.

The installed combined fire hydrant/fire sprinkler system, compliant with AS2118.6, was designed to facilitate simultaneous operation of four sprinkler heads and two fire hydrants. See Appendix 8.(full report) It is possible that not all sprinkler heads along with the two fire hydrants were operating at the 


\section{MATEC Web of Conferences}
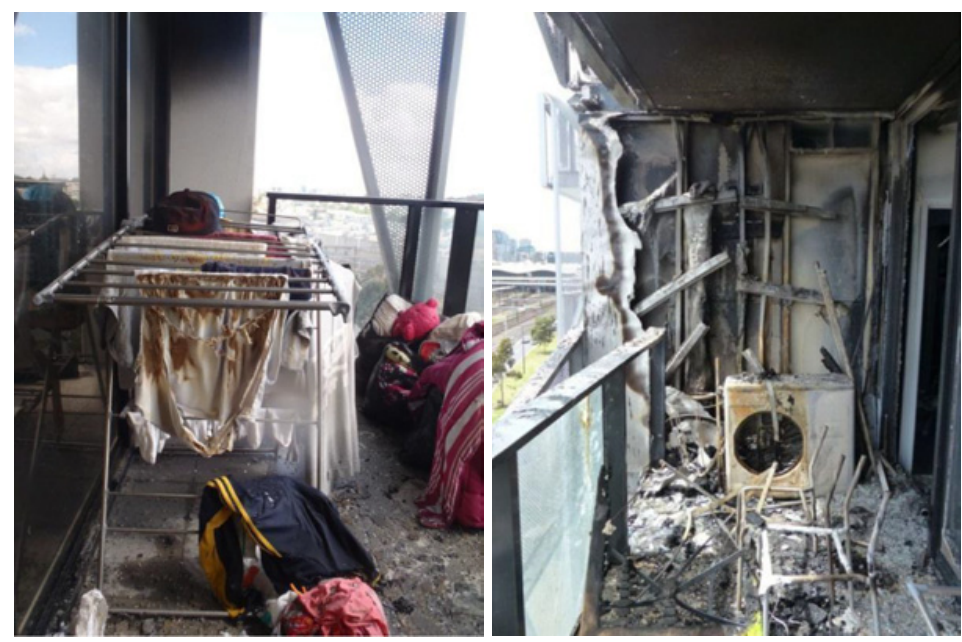

Figure 3. Picture of typical combustibles present on balconies.

same time; however due to the time-line of events, it is reasonable to conclude that the system operated significantly beyond its designed capability.

Had the combined fire hydrant/fire sprinkler system not exceeded its designed capability, it is likely that significant fire development and spread would have occurred in some of the subject apartments on Levels 6 to 21. Spread beyond the subject apartments to adjacent apartments and common areas may also have occurred.

This would have presented an extremely difficult scenario for fire-fighters and occupants of the building, and may have resulted in serious injury and/or death. Significantly increased property damage and loss would have occurred along with the negative impact on occupant displacement and emergency service/recovery agency resource.

\subsection{Sprinklers were not required on the balconies under the BCA}

\subsection{MFB comment:}

The balconies connected to Apartments 605 to 2105 were approximately 1.8 metre in depth $\times 4.7$ metre long. The sprinkler system did not extend beyond the apartments" internal areas to the balconies and it is acknowledged by the MFB that this was not a deemed-to-satisfy requirement under the Building Code of Australia (AS2118.1 Sect. 5.7.10).

\section{AS 2118.1 Sect. 5.7.10 - Covered balconies}

Portions of covered balconies that exceed $6 \mathrm{~m}^{2}$ floor area and have a depth in excess of $2 \mathrm{~m}$ shall be sprinkler protected.

The Chief Officer Report and Consent pursuant to Regulation 309 of the Building Regulations 2006, dated 29 March 2011, contains notification under 309(3) for the deletion of sprinklers to balconies (not Apartments 605 to 2105) and indicated the balconies in question would have low fuel loads. MFB recommendations included a comment that balconies were not to be used for storage and requested that this measure was to be included as part of the Essential Safety Measures for the building.

In this instance, typical combustibles identified to be present on balconies throughout the building consisted of clothing, bedding, bicycles, electrical appliances and other miscellaneous combustible materials, notwithstanding the air conditioner compressor units and other combustible furniture items (see Fig. 3). 
High occupancy rates in apartments can lead to reliance on balconies for additional storage space, increasing the fire load.

Had the sprinkler system extended to the balcony area of each apartment, fire would have most likely been contained to the level of fire origin.

\section{CONCLUSION}

In this instance, fire quickly extended up the external wall involving the cladding and fuel loads on each balcony. Had the external wall cladding been of a non-combustible type, the likelihood of fire spread beyond the level of ignition would have been greatly reduced.

Furthermore, if a sprinkler head had been installed, it too would have reduced the chance of fire spread.

In the words adopted within the Building Code of Australia, a building must have elements to the degree necessary to avoid the spread of fire in a building. Amongst other considerations, the degree necessary is relative to:

- The function and use of the building - residential building with sleeping occupants not in a ready and aware state.

- The fire hazard - the installed cladding material appeared to be a readily combustible material, which upon ignition sustained and supported rapid spread of fire. Additionally, there was excessive storage of combustibles on many of the balconies.

- The number of storeys - the building contains 23 storeys (high-rise).

- Fire brigade intervention - High-rise, 400+ occupants and multiple internal ignitions over 15 floors.

The fire behaviour on the morning of the 25 November 2014, clearly demonstrated to all concerned, that the elements installed to the external walls of this building did not avoid the spread of fire to the degree necessary.

An improved system and understanding for ensuring appropriate material selection, approval and installation is of major importance to the MFB.

There were many contributory factors leading to the events on 25 November 2014. In this instance, increased combustible fuel loads on the unsprinklered balcony aided in the ignition and fire propagation to such a degree, as to allow ignition of the external wall cladding. This incident in isolation may have resulted in a far more manageable outcome with damage on one level only. However, as previously described in this report, rapid fire spread directly related to the involvement of the external cladding material, occurred to such an extent that the only likely fact preventing further vertical fire spread was the limitation of the building height to only 21 storeys.

Clearly, the external cladding material on this building did not to the degree necessary avoid the spread of fire as required by the Building Code of Australia. Simultaneous internal fire ignition events over multiple floors are simply an unacceptable fire safety solution for a residential high-rise building, or any other occupiable building for that matter.

If not for the excellent performance of the internal fire sprinkler system and the quick and professional response of the MFB fire-fighters to prevent further internal fire spread and development, the consequences of this fire would likely have resulted in greater impact on occupants, the surrounding community amenity, resources and infrastructure. There could have been a greater likelihood of serious injury or even loss of life.

Whilst damage and injury were minimised, the social impact of this fire was considerable and cannot be ignored. All occupants of the building were displaced for some days during building refurbishment and reinstatement of the fire safety systems, whilst the occupants of the fire affected apartments were displaced for considerably more time. Prevention of similar incidents in new and existing developments 


\section{MATEC Web of Conferences}

should be a priority for the entire construction industry. This must start with ensuring an improved process and/or understanding for appropriate material selection, approval and installation. In particular, the MFB would urge all stakeholders in the construction industry to exercise greater diligence and caution with the selection and installation of aluminium/polyethylene composite cladding panels, and encourage selection of those products with appropriate and clear product accreditation and certificates of conformity. Given the risk of fire on a residential balcony is real, and as in this instance, the sprinkler system within the apartments does not extend to protect the balcony on each level, there is the possibility for this scenario to repeat itself.

The full Post Incident Analysis (PIA) report can be located at the following link:

http://www.mfb.vic.gov.au/Media/docs/Post_Incident_Analysis_ Lacrosse_ Docklands-f699bfbc-344a-4168-bdd8-ef8aa5e61c1e-0.pdf 